\title{
Six Steps to Help Artists Thrive as Entrepreneurs
}

\author{
Sarah Marty (Wisconsin School of Business, University of Wisconsin-Madison)
}

\author{
KEYWORDS: Arts, Entertainment \& Recreation, \\ Entrepreneurship, Finance.
}

For centuries, in many cultures, a career as an artist has centered on public performances, public exhibitions, and public perceptions of perfection and virtuosity. As artists we've hidden the thousands of hours spent perfecting our craft - practicing scales and technical exercises, honing control of every muscle in our bodies, building up layers on a canvas. You've probably heard the famous maxim, "How do you get to Carnegie Hall? Practice." In the private space of studios, practice rooms, and rehearsal halls, we understand that practice means failing often and learning from those micromistakes, building your artistic practice and advancing your technique.

Yet, in other aspects of our lives and careers we artists often lose our confidence in that honed discipline of practice, reflect, revise. The competition to be the "best" - to win a seat in an orchestra, to be awarded a fellowship or a prize, to get a good review from a professional theatre critic, to land a job at the Performing Arts Center - has taught us that we must be excellent before we share with someone else and this, in many case, discourages collaboration. Beyond that, once we graduate, we lose access to the tools, materials, equipment, and community that we've been part of during our college careers and have little idea how to proceed in the professional realm.

As a teacher, my goal in mentoring arts entrepreneurs is to support students as they learn to apply the transferable skills of all artistic practices - that cycle of theory, discipline, reflection, and revision - in a business setting and to recognize that they are, in fact, entrepreneurs and can claim that title, and the tools and frameworks of entrepreneurship, as their own.

\section{Overcoming Barriers}

During our first day of classes, students often say things like "I'm not a numbers person." or "I'm nervous about taking a business class." The first barrier for artists is

the perception that artists don't -- or, worse yet, can't -understand business. Many have internalized this and other tropes like "You can't make a living as an artist." and "The Arts are less important than Science, Technology, Engineering, and Math."

The "Introduction to Arts Entrepreneurship" course that I teach through the Bolz Center for Arts Administration in the Wisconsin School of Business at University of Wisconsin-Madison is designed to challenge those negative perceptions by helping students build their business toolkits and to apply those frameworks to arts projects they are passionate about.

At its foundation, entrepreneurship is making things happen with the available resources within an allotted timeline and budget. Those working in the arts and cultural sector could be considered the ultimate entrepreneurs as they are often creating work and programming on incredibly tight budgets and doing so in a way that responds to a dual-bottom line: mission (or impact) and financial sustainability.

\section{Six Key Objectives}

Key Objectives for the course are applicable for any arts student looking to leverage their artistic expertise and pursue a career in the arts and cultural sector. And, I've broadened the discussion of these objectives to include practical advice for artist entrepreneurs who are trying to make a living from their art now.

1. Foster and Build Community: Our classroom is a place where we lift each other up and celebrate the diversity of experiences, talents, skills, and interests that each student brings to the table. As part of this process, we work in teams who serve as a collaborative peer group providing feedback on ideas in early stages, reviewing completed projects and offering both compliments and suggestions, and reflecting on contemporary case studies and issues in the arts and cultural sector. In doing so, we foster

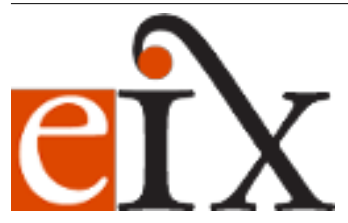

Copyright ( ) 2021 The Authors. Entrepreneur \& Innovation Exchange is published at EIX.org. This is an open access article under the terms of the Creative Commons Attribution-NoDerivs License, which permits use and distribution in any medium, provided the original work is properly cited and no modifications or adaptations are made. View EIX.org Authorship Terms at https://eix.org/terms 
the spirit of collaboration and learn how to build community with others, a skill that can help bridge the gap between college and the "real world." As artists, we often practice and create alone so it is important to be able to reach out to others, to find community across artistic disciplines, and to be open to offering and receiving feedback.

2. Define "The Big Three" for ourselves and for arts and cultural organizations. We ask, "Who are you? What do you do? Why does it matter?" and later "How can I help?" As we refine these elevator pitches throughout the semester and also apply the framework to other individuals and companies, we home in on mission, vision, and values. Being able to articulate responses in written and verbal forms helps us communicate the value of our work, articulate the community impact, and encourage others to take action - as an audience member, as a donor, as a business partner, and/or as a supporter.

3. Frameworks and Tools are helpful. Just as we have techniques and exercises to advance our artistic skills, there are business frameworks and tools that can be used to leverage our artistic expertise in a variety of settings, to communicate and build towards career objectives, and to create a plan to bring an artsbased business from idea to reality. As an example, in our class we learn how to create a micro-podcast, to build a personal website, and to create a standard business plan for an artistic endeavor. All of these are activities that an artist entrepreneur can practice on their own. A few open source tools you can use to get started include the NPR "How to Start a Podcast" Life Kit

(https://www.npr.org/2021/06/22/1009098800/h ow-to-start-a-podcast-npr-advice) and the "Work of Art: Business Skills for Artists" and "Handbook for Artists Working in Community" workbooks created by Springboard for the Arts (https://springboardforthearts.org/buy-books/) .

4. Realize that "You can't boil the

ocean." Approach each project in small pieces. Create a timeline and outline the key components that you'll need to figure out to make it happen. You might not have all of the answers, but the first step is creating a plan and then starting to research. Along the way, know that things may change as you learn more and gather more information and that's okay. Projects, like life, are rarely a straight line. Being nimble and open-minded is important.

5. It's okay, and encouraged, to ask for help. A huge part of working in the arts is recognizing your own strengths and identifying your weaknesses. Some are things that you might enjoy learning about and dedicating time to while others are better outsourced to another person or company. Yes, you can learn all about financial accounting but maybe your time is better spent rehearsing a play than spending hours on Quickbooks. The key is to know what needs to be done, to find a reputable partner to work with, to outline expectations and tasks, and to create and execute a contract that outlines terms and conditions.

6. Recognize that the arts are part of building towards a more just and equitable society. As we rebuild after The Great Pause, those who work in the arts and cultural sector should have a seat at the table, as equal partners who can bring innovative thinking and solutions to community and civic issues. With great challenge comes great opportunity - rather than carrying forward existing systems, we can look to two successful projects for inspiration on how arts activists have leveraged policy toward positive community outcomes: the Minnesota Legacy Amendment (2009) that prioritized the quality of life for their state's citizens and codified that commitment in their constitution and the decade-long ArtPlace America Creative Placemaking initiative that funded artist-driven solutions to community challenges in locales all across the country.

\section{Being Comfortable in Both Realms}

In conclusion, while the traditional preparation of an artist emphasized intensive training in their discipline, makers now must develop their craft and manage their entrepreneurial endeavors. They may serve as their own agents, run their own labels, and manage the "business" of their art, including marketing, production, accounting, and more as they develop their careers. New technologies make this possible - even exciting -but we must first welcome artistic professionals into the classroom where they can see how their preparation as artists complements the cultivation of their managerial 
savvy and entrepreneurial skills.

Artists who appreciate the value of community, who have a bias to action and a willingness to learn from mistakes, and who can "pitch" themselves and their work effectively combine the best of artistic practice and entrepreneurial methods, and they are needed to lead our arts and culture organizations and to strengthen our communities. 